\title{
Sportsmen's Panel - CKDM Dauphin
}

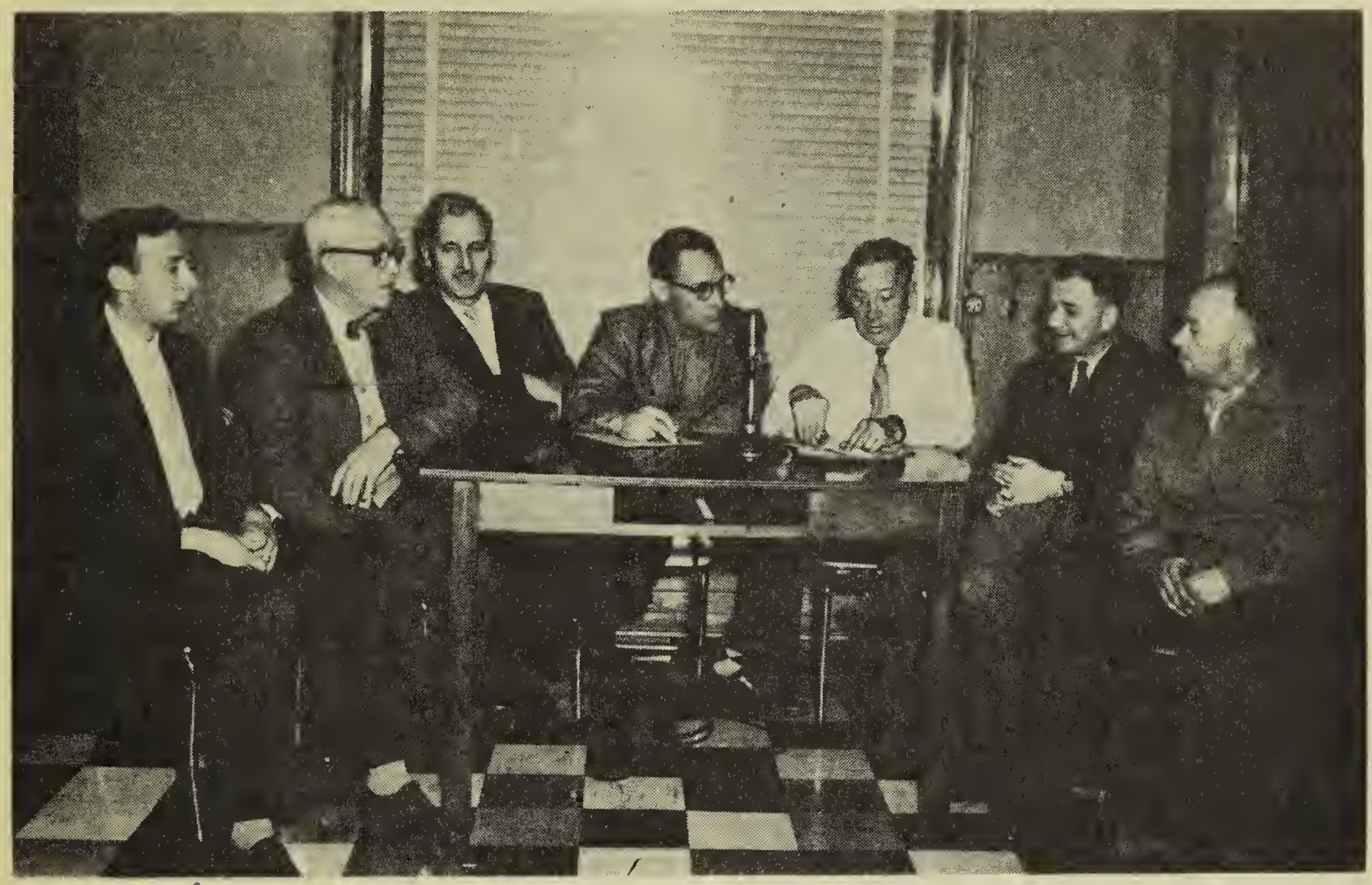

-Krass Studio

SPORTSMEN'S PANEL: March 11, 1956. Left to right: Stan Martinson, (Rod and Gun Club, Ortonville, Minn., guest), Dr. O. McGuirk (Veterinarian, Dominion Government, guest), W. T. Forbes, J. Ludgate (Moderator), Art Mansoff ("The Old Poacher"), Dr. C. C. Wright, (Medical Health Director, Manitoba, guest), Sid Glinnon.

Every Sunday afternoon at 2:30 p.m. Radio Station CKDM in Dauphin, Manitoba, broadcasts as a public service feature a half-hour programme called Sportsmen's Panel. Broadcast time is used to discuss important problems in wildlife conservation. In addition, the panel selects each week the most interesting letter submitted to it and awards a year's subscription of the Blue Jay to the writer. Frize-winning letters have described dogs turning deer killers, the habits and nesting of Canada and Blue Jays, feeding of upland birds around grain elevators, muskrat farming and the planting of wild rice for ducks, etc. We are pleased to have the Blue Jay going into the homes of these Manitoba people who are interested in wildlife.

\section{BLUE JAY WANTED}

We need a back copy of the Blue Jay, Volume X, Number 3, July, August, September, 1952 to complete a file of the Blue Jay. If you know of an extra copy of this issue, which is not needed, please send it to 2335 Athol St., Regina. If new members would like back copies we have all the 1954 and 1955 copies available and will sell the 8 as a set for $\$ 1.00$. 